\title{
Surgical treatment of relapsed megaesophagus
}

\section{Tratamento cirúrgico do megaesôfago recidivado}

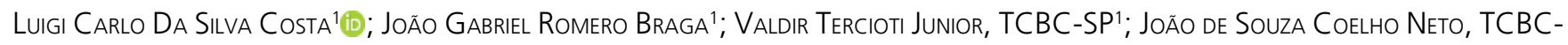

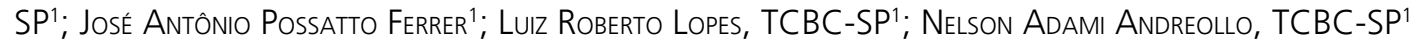

\section{A B S T R A C T}

\begin{abstract}
Objective: to analyze the surgical treatment of patients with recurrent megaesophagus followed at the esophageal-stomach-duodenal outpatient clinic of the Hospital de Clínicas - UNICAMP. Methods: a retrospective study, from 2011 to 2017, with 26 patients with Chagas or idiopathic megaesophagus, surgically treated, and who recurred with dysphagia. Clinical, endoscopic and radiographic aspects were assessed and correlated with the performed surgical procedures. Results: $50 \%$ had dysphagia for liquids, $69 \%$ regurgitation, $65.3 \%$ heartburn, $69.2 \%$ weight loss and $69.2 \%$ had Chagas disease. In addition, 38.4\% had megaesophagus stage 1 and 2 and $61.5 \%$ stage 3 and 4 . Regarding the reoperations, $53 \%$ of them underwent Heller-Pinotti surgery by laparoscopy, Serra-Dória in $30.7 \%$ and esophageal mucosectomy in $7.9 \%$. In $72 \%$ of the reoperations there were no postoperative complications, and $80 \%$ of the patients had a good outcome, with reduction or elimination of dysphagia. Among the reoperated patients undergoing the laparoscopic Heller-Pinotti technique, three reported little improvement of dysphagia in the postoperative period and among those who underwent Serra-Dória surgery, $100 \%$ had no dysphagia. It was observed that, when the time between the first procedure and the reoperation was longer, the better the surgical result was, with statistical significant decreased dysphagia $(p=0.0013, p<0.05)$. Conclusions: there was a preference to perform laparoscopic re-miotomy and, as a second option, Serra-Dória surgery, for patients with recurrent megaesophagus. Esophagectomy or esophageal mucosectomy were reserved for more severe patients.
\end{abstract}

Keywords: Esophageal Achalasia. Heller Myotomy. Reoperation.

\section{INTRODUCTION}

A chalasia is a relatively rare primary disorder of the motor esophagus and has the idiopathic form as the most prevalent on all continents. Currently, it is estimated that eight million people are infected with Trypanosoma cruzi worldwide, mostly in Latin American countries, where the parasite is endemic. However, cases of Chagas disease have been increasingly detected in the United States, Canada and many European countries, due to the increase in migratory movements between Latin America and other continents. This disease is potentially fatal and is characterized by an acute phase lasting approximately two months with few or no symptoms, and a chronic phase, which is lifelong if antiparasitic treatment is not administered or is not successful. This chronic condition is asymptomatic in most cases, but among the symptomatic cases, those of gastrointestinal origin predominate, having a great impact on quality of life ${ }^{1-3}$.

The symptoms of esophageal achalasia are due to the lack of esophageal peristalsis and the functional obstruction of the Gastresophageal Junction (GEJ), secondary to the loss of the physiological function of the lower esophageal sphincter. One objective way of assessing the severity of the symptoms of esophageal achalasia, as well as the efficacy of treatment, is the Eckardt score, ranging from 0 to 12 points, which classifies the disease stages. The score assigns 0 to 3 for weight loss, dysphagia, chest pain and regurgitation, the final value consisting of the sum of these items: stage 0 (0-1 points), stage I (2-3 points), stage II (4-6 points) and stage III (> 6

1 - Faculty of Medical Sciences / UNICAMP, Department of Surgery - Campinas - São Paulo - Brazil 
points). The goal of treatment is to restore the ability to feed orally and to alleviate all of these symptoms, which can be achieved by several treatment modalities, such as endoscopic dilation, perioral endoscopic myotomy, and laparoscopic Heller Pinotti cardiomyotomy, which is currently considered the standard treatment for nonadvanced megaesophagus. These modalities eliminate the GEJ food outflow resistance, improving esophageal emptying. Esophagectomy is the option of choice when symptoms recur or in advanced megaesophagus, but it adds greater morbidity and mortality associated with thoracic esophageal dissection. An alternative to esophagectomy is the esophageal mucosectomy proposed by Aquino et al. with less morbidity due to the preservation of the esophageal muscle tunic and an intra-luminal dissection of the esophageal mucosa with subsequent transposition of the gastric tube without violation of the mediastinum ${ }^{4-6}$.

Recurrence of dysphagia after cardiomyotomy is associated with gastroesophageal reflux with esophagitis, incomplete myotomy, fibrosis at the site of the gastroesophageal junction, indication of improper technique for patients with advanced megaesophagus, and intrathoracic migration of the gastric fundus. Reoperation is usually not very successful in relation to the first procedure and many patients require esophageal resection, with the possible associated complications. The appropriate choice of surgical treatment for recurrent achalasia depends on the recurrence's pathophysiological mechanism. Therefore, for patients with incomplete myotomy or fibrosis at the esophagogastric junction, a new myotomy with partial fundoplication is still indicated, as long as the esophageal wall has not been damaged during dissection. For patients with significant reflux or dolichomegaesophagus, the indication is esophagectomy with the transposition of a gastric or colonic tube. Another option in achalasia reoperation has been the Serra-Dória procedure, consisting of a long latero-lateral anastomosis between the distal esophagus and the gastric fundus, associated with a Roux en $Y$ partial gastrectomy to facilitate emptying and preventing esophageal bile reflux. The present study aimed to retrospectively evaluate the surgical treatment and the evolution of patients with recurrent megaesophagus in a university hospital6-8.

\section{METHODS}

We carried out a revision of medical records at the Hospital de Clínicas of UNICAMP, from 2011 to 2017. We identified $26(\mathrm{~N})$ patients with the diagnosis of megaesophagus who required reoperation due to the return of achalasia symptoms, mainly dysphagia.

The variables collected for the study for each patient were age, sex, comorbidities, classification of the megaesophagus, number of esophageal calibrations, time between surgical procedures, time of postoperative follow up, esophageal symptoms, weight loss, number of surgeries, postoperative complications, and evolution of dysphagia. We correlated all these variables with the patient's postoperative evolution. We considered satisfactory progress or therapeutic success the patients who had improved dysphagia or complete resolution of symptoms, with no impact on quality of life. Unsatisfactory evolution was a worsening of the dysphagia degree.

Statistical analysis included the Spearman's correlation coefficient and the Mann-Whitney and Kruskal-Wallis tests for numerical variables. We adopted the Fisher's exact test for categorical variables. The level of significance was $5 \%$.

This study was approved by the UNICAMP Ethics in Research Committee (opinion No. 2, 532, 542).

\section{RESULTS}

Of the $26(\mathrm{~N})$ patients studied, there was a predominance of males (57.69\%). The average age of the patients at the time of reoperation was 65.65 years.

Figure 1 represents the degree of dysphagia, in addition to the time between the first megaesophagus surgical approach and the reoperation. Dysphagia for liquids was more prevalent, in $50 \%$ of cases. The duration of dysphagia, which corresponds to the time between the two surgical approaches, was on average nine years. Patients who had symptoms recurrence with indication of reoperation showed an average of 7.36 endoscopic dilations.

The most prevalent signs and symptoms were weight loss (69.23\%), regurgitation (69.00\%) and heartburn (65.38\%), as indicated in Figure 2. Heart disease was present in $38.46 \%$ of patients, and megacolon, in $30.77 \%$ (Figure 2). 

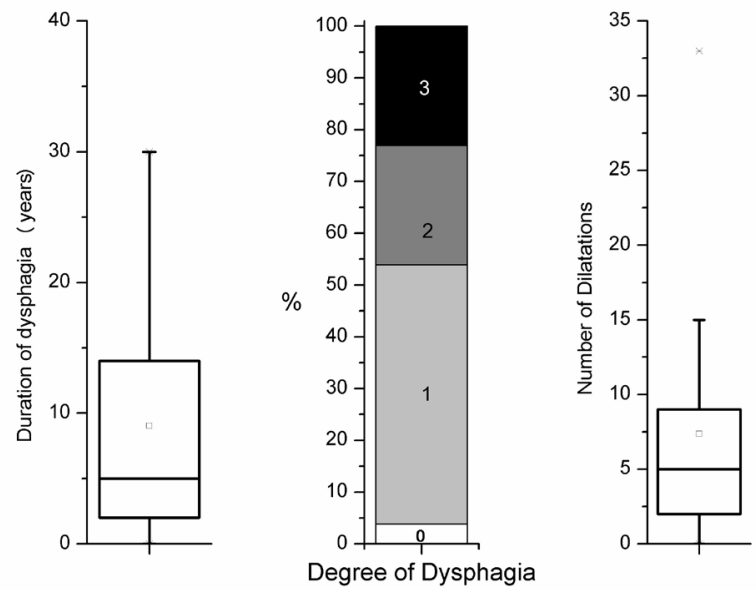

Figure 1. Box-plot of dysphagia duration (in years) and the number of dilations and distribution of dysphagia intensity.

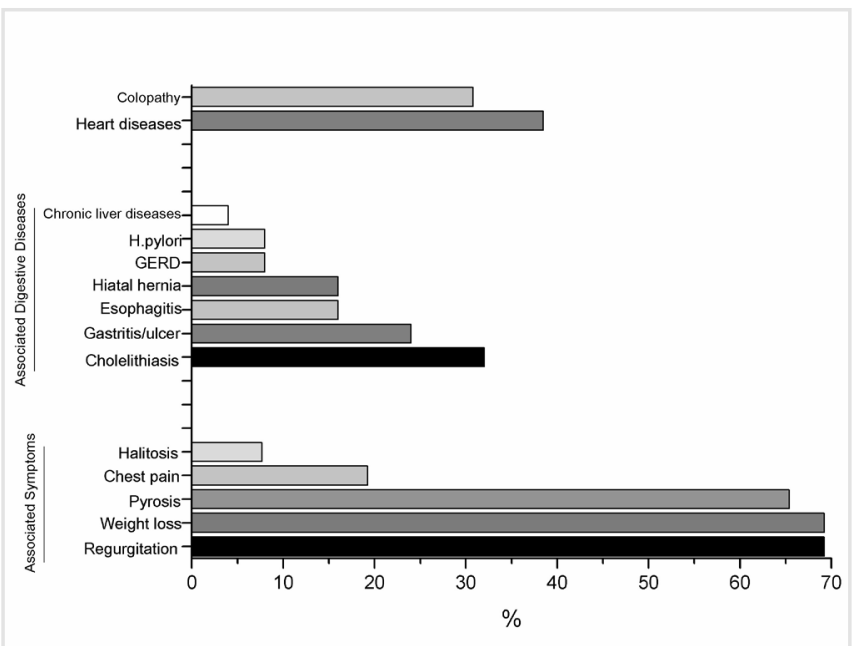

Figure 2. Distribution of symptoms and associated digestive diseases.

Figure 3 shows that Chagas disease was predominant (69.23\%) among the patient's comorbidities.

Traditionally, megaesophagus is graduated according to the largest diameter observed in the barium swallow examination. In this series, achalasia stages in 1 and 2 were present in 38.46\%, and stages 3 and 4, in $61.54 \%$ (Figure 4 and Table 1). In $53.00 \%$ of the reoperations, the laparoscopic Heller-Pinotti technique was the choice, Serra-Dória in $30.77 \%$, and mucosal resection in $7.96 \%$. Surgical treatment of recurrent megaesophagus displayed better results among cases with more advanced disease $(61.50 \%)$, than in nonadvanced ones (38.50\%). All patients undergoing the Serra-Dória procedure and $78.57 \%$ of individuals undergoing the Heller-Pinotti surgery had a satisfactory outcome, with improvement in dysphagia, but without statistical difference.

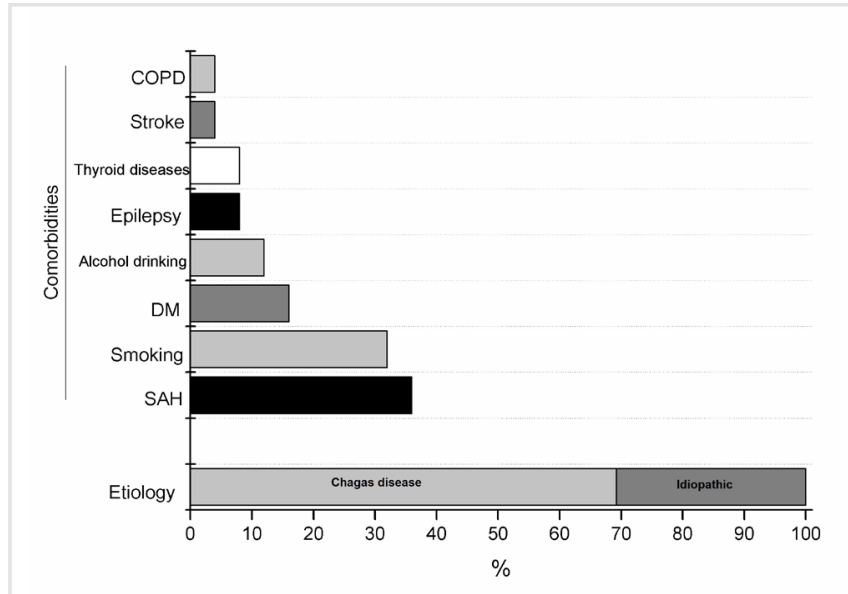

Figure 3. Distribution of comorbidities and the megaesophagus etiology.

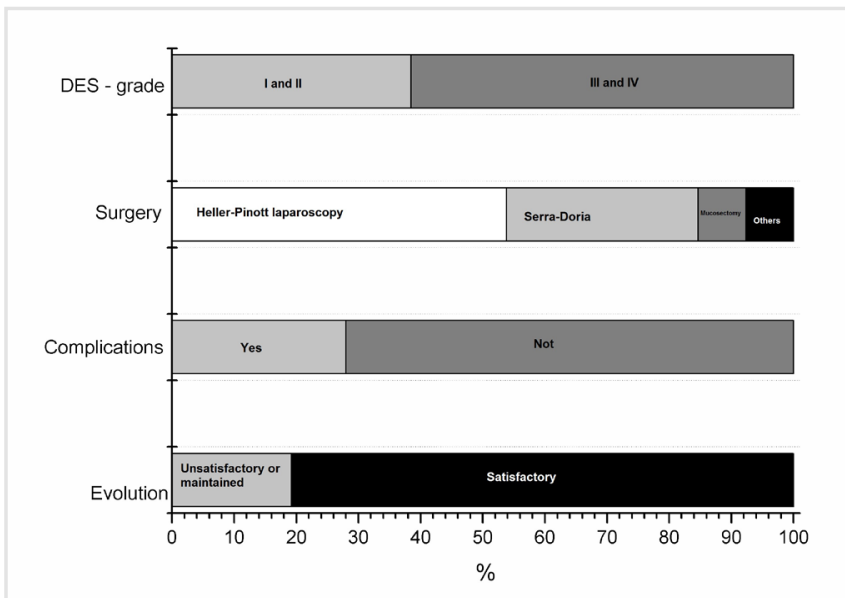

Figure 4. Megaesophagus stage, type of reoperation, postoperative complications, and dysphagia evolution.

Among the complications of surgical treatment, we identified two cases of pneumonia, two cervical fistulas, one esophageal perforation, one case of pulmonary thromboembolism, and one evisceration. Among the patients who developed early recurrence of dysphagia (5 cases), two had undergone esophageal mucosal resection, and evolved with fistula and dysphagia, and three patients had been submitted to Heller-Pinotti, one displaying dysphagia for liquids in the immediate postoperative period. 
Table 1. Evolution of dysphagia in the postoperative period according to megaesophagus degree, type of surgery, number of surgical procedures per patient, and postoperative complications

\begin{tabular}{|c|c|c|c|c|}
\hline \multirow[t]{2}{*}{ Variable } & \multicolumn{2}{|c|}{ Evolution of dysphagia } & \multirow[t]{2}{*}{ Total } & \multirow[t]{2}{*}{$\mathrm{p}^{*}$} \\
\hline & $\begin{array}{c}\text { Unsatisfactory or } \\
\text { unaltered }\end{array}$ & Satisfactory & & \\
\hline \multicolumn{5}{|c|}{ Preoperative megaesophagus } \\
\hline Grade I-II & $2(40 \%)$ & $8(38.1 \%)$ & $10(38.5 \%)$ & \\
\hline Grade III-IV & $3(60 \%)$ & $13(61.9 \%)$ & $16(61.5 \%)$ & 1.0000 \\
\hline \multicolumn{5}{|l|}{ Surgery } \\
\hline Heller-Pinotti & $3(60 \%)$ & $11(52.4 \%)$ & $14(53.8 \%)$ & \\
\hline Serra-Dória & $0(0 \%)$ & $8(38.1 \%)$ & $8(30.8 \%)$ & \\
\hline Other & $2(40 \%)$ & $2(9.6 \%)$ & $4(15.4 \%)$ & 0.1031 \\
\hline \multicolumn{5}{|c|}{ Number of procedures } \\
\hline 2 & $5(100 \%)$ & $16(76.2 \%)$ & $21(80.8 \%)$ & \\
\hline 3 & $0(0 \%)$ & $5(23.8 \%)$ & $5(19.2 \%)$ & 0.5451 \\
\hline \multicolumn{5}{|c|}{ Postoperative complication } \\
\hline Yes & $2(40 \%)$ & $5(25 \%)$ & $7(28 \%)$ & \\
\hline No & $3(60 \%)$ & $15(75 \%)$ & $18(72 \%)$ & 0.5968 \\
\hline
\end{tabular}

Figure 5 demonstrates the correlation between age, duration of dysphagia, number of dilations and time between surgeries with the evolution of dysphagia. The only statistically significant result was the association between a longer duration of dysphagia and better postoperative results $(p=0.0013)$. This chart shows that the five cases with unsatisfactory results had the time between the first and second surgical approach less than five years, which may have impacted the unfavorable outcome.

Figure 6 brings the correlation between the main symptoms and comorbidities with the development of postoperative dysphagia. We observed a tendency towards a predominance of heartburn and regurgitation in cases of unsatisfactory evolution, but without statistical significance.

Figure 7 depicts the preoperative Eckardt score and the postoperative follow-up time with the response to the treatment for recurrent megaesophagus. The postoperative follow-up time was the difference between the date of data collection (06/15/2018) and the date of the last surgery.

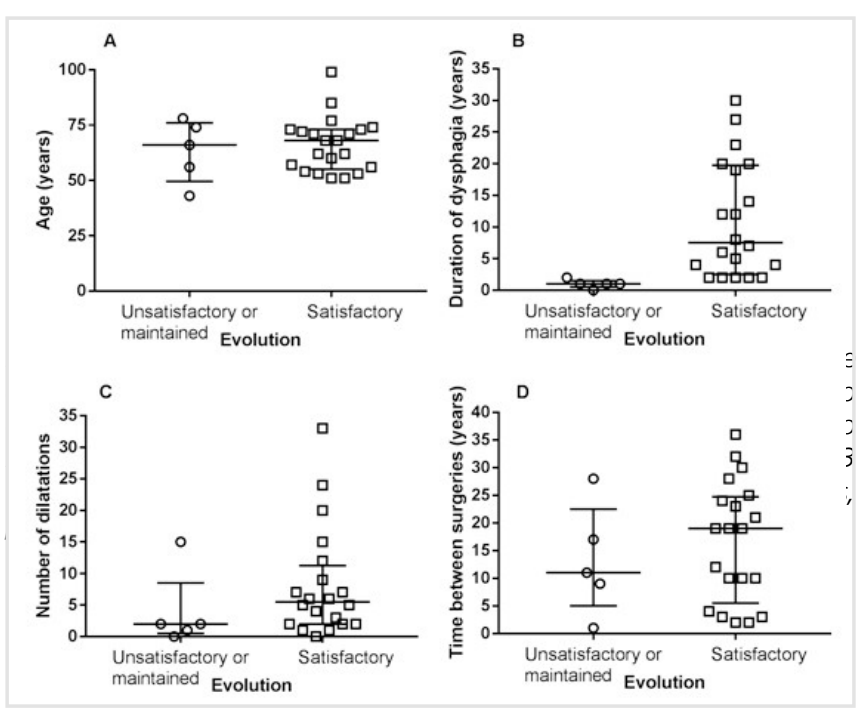

Figure 5. Dispersion of age (A), duration of dysphagia (B), number of dilations $(C)$ and time between surgeries (D) between the dysphagia evolution categories. The horizontal lines represent the median and the interquartile range. There is a significant difference $(B), p$-value $=$ 0.0013 , Mann-Whitney test. No statistical significance for the others, $p=1.0000(A), p=0.1419(C)$ and $p=0.4539(D)$. 


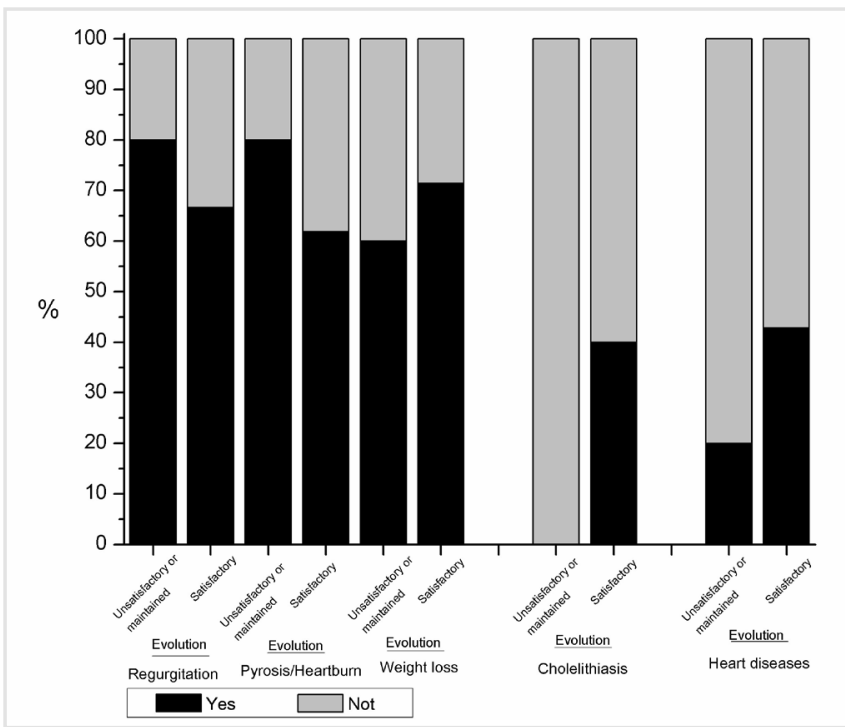

Figure 6. Dysphagia evolution according to symptoms and associated diseases. There was no significant difference for the variables, $p=1.0000$ (regurgitation), $p=0.6279$ (heartburn), $p=0.6279$ (weight loss), $p=0.1399$ (cholelithiasis) and $p=0.6169$ (heart disease). Fisher's exact test.
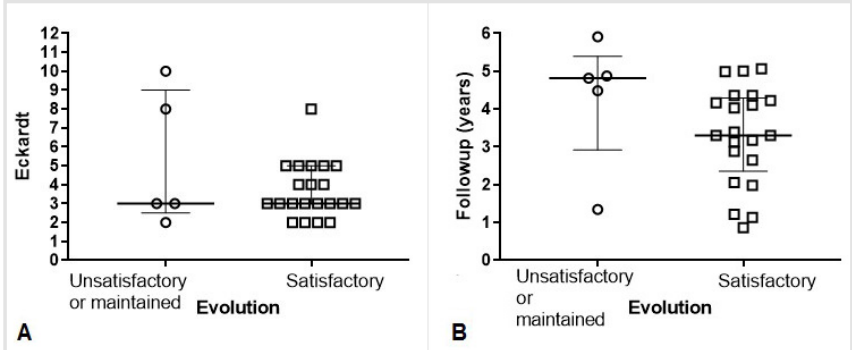

Figure 7. Distribution of the Eckardt score $(A)$ and length of followup in years $(B)$ between the categories of dysphagia evolution. The horizontal lines represent the median and the interquartile range. There was no statistical significance, $p=0.6607$ (A) and 0.1037 (B), Mann-Whitney test.

\section{DISCUSSION}

The analysis of dysphagia degree in patients with recurring megaesophagus, with regard to symptoms recurrence, is important, since it defines the inability to transfer the food bolus, affecting the patient's quality of life and leading to serious complications such as severe malnutrition. We evaluated the patients in a postoperative time interval that varied from 1 to 6 years after the reoperation and there was a homogeneous dispersion among those who progressed satisfactorily. What drew attention was that the patients considered to have an unsatisfactory evolution, remained in clinical follow-up with endoscopic dilations during a 5-year postoperative period without having had another surgical approach. All of these patients are followed at the Gastrocentro/ UNICAMP endoscopic dilation clinic with the purpose of esophageal calibration and symptom relief in the postoperative follow up. Moreover, it is known that the relief of dysphagia with periodic cardia dilation allows delay reoperation in young individuals and it does not cause negative impact on surgical outcome, since these were the patients who had better results ${ }^{4,9,10}$

The most prevalent signs and symptoms among our patients, when compared to the literature, show little divergence, as in other studies chest pain predominates at the expense of weight loss. In addition, we found that the most prevalent symptoms in the megaesophagus comprise the Eckardt score. For patients who progressed satisfactorily in the postoperative period, there was a predominance of Eckardt stages 1 and 2, but without statistical significance.

The predominance of chagasic etiology in this study is compatible with all Brazilian literature and with the epidemiology of Latin America. When analyzing cases of achalasia on other continents, the etiology remains uncertain. However, cases of Chagas disease have been increasingly detected in the United States, Canada and in many European countries, due to migratory movements between Latin America and other continents. Trypanosoma cruzi has tropism for the heart and gastrointestinal tract, causing diseases such as megacolon and heart failure ${ }^{1-3,7,11,12}$.

Ponciano et al. reported rates of postoperative success similar to this study in patients with relapsed megaesophagus when choosing the Serra-Dória surgery as the first alternative, even demonstrating regression of the esophagus diameter in postoperative contrast examinations. Esophagectomy and mucosal resection are indicated for advanced megaesophagus in patients with good clinical condition and when there are poor results with re-myotomy ${ }^{7,13}$

Some authors describe the reasons for recurrence of dysphagia symptoms after surgery, highlighting the associated reflux disease, the presence of fibrosis at the cardiomyotomy site, short cardiomyotomy, and inadequate indication of the technique. In the present study, of the three patients who progressed poorly after Heller-Pinotti surgery, one had a previous diagnosis of 
stage 3 megaesophagus, reinforcing the importance of the correct indication of the surgical technique according to the disease stage. It was not possible to establish the reason for the other two unfavorable outcomes ${ }^{7,14}$.

\section{CONCLUSION}

The present study was able to determine the conduct profile of our service regarding the treatment of recurrent megaesophagus, with preference for a new cardiomyotomy by laparoscopic Heller-Pinotti and the Serra-Dória surgery. The latter was a good option for both non-advanced and advanced megaesophagus. The longer dysphagia time between the first and second procedures correlated with greater therapeutic success in the postoperative period, which points to the benefit of periodic esophageal dilatation in these patients follow up. Moreover, detailing of disease extent, symptoms, associated comorbidities and surgical complications should be considered to identify the cause of recurrent achalasia, as it affects decision-making towards the best treatment. It is important, however, to emphasize that this study had a small sample, which makes it difficult to find significant results.

\title{
R E S U M O
}

\begin{abstract}
Objetivo: analisar o tratamento cirúrgico dos pacientes com megaesôfago recidivado acompanhados no ambulatório de cirurgia de esôfago-estômago-duodeno do Hospital de Clínicas da UNICAMP. Métodos: estudo restrospectivo no período de 2011 a 2017 , com 26 pacientes portadores de megaesôfago chagásico ou idiopático, tratados cirurgicamente e que evoluíram com recidiva da disfagia. Foram avaliados aspectos clínicos, endoscópicos e radiográficos, sendo correlacionados com os procedimentos cirúrgicos realizados. Resultados: 50\% apresentava disfagia para líquidos, 69\% regurgitação, 65,3\% pirose, 69,2\% perda de peso e 69,2\% era chagásico. Além disso, 38,4\% apresentavam megaesôfago estágio 1 e 2 e 61,5\% estágio 3 e 4. Quanto às reoperações, em 53\% foi realizada a cirurgia de Heller-Pinotti videolaparoscópica, seguida de Serra-Dória em 30,7\% e mucosectomia esofágica em 7,9\%. Em 72\% das reoperações não houve complicações pós-operatórias e $80 \%$ tiveram evolução satisfatória com redução ou ausência da disfagia. Dentre os pacientes reoperados pela técnica de Heller-Pinotti videolaparoscópica, três referiram pouca melhora da disfagia no pós-operatório. Dentre os pacientes submetidos à cirurgia de Serra-Dória, 100\% tiveram evolução satisfatória da disfagia. Foi observado nos pacientes com o tempo entre a primeira cirurgia e a reoperação mais longo, um melhor resultado cirúrgico com diminuição da disfagia, com relevância estatística $(p=0,0013, p<0,05)$. Conclusão: houve preferência nas reoperações de megaesôfago pela realização de remiotomia por videolaparoscopia e, como segunda opção, a cirurgia de Serra-Dória. A esofagectomia ou mucosectomia esofágica foram reservadas para os casos mais avançados.
\end{abstract}

Palavras chave: Acalasia Esofágica. Miotomia de Heller. Reoperação.

\section{REFERENCES}

1. Zaninotto G, Bennett C, Boeckxstaens G, Costantini M, Ferguson MK, Pandolfino JE, Patti MG, Ribeiro U Jr, et al. The 2018 ISDE achalasia guidelines. Diseases of the Esophagus. 2018;31(9):1-29.

2. Albajar-Viñas $P$, Dias JCP. Advancing the treatment for Chagas' disease. N Engl J Med. 2014;370(20):1942-3.

3. Souza DH, Vaz Mda G, Fonseca CR, Luquetti A, Rezende Filho J, Oliveira EC. Current epidemiological profile of Chagasic megaesophagus in Central Brazil. Rev Soc Bras de Med Trop. 2013;46(3):31621.

4. Schlottmann F, Andolfi C, Kavitt RT, Konda VJA, Patti MG. Multidisciplinary approach to esophageal achalasia: a single center experience.
J Laparoendosc Adv Surg Tech A. 2017;27(4):358362.

5. Laurino Neto RM, Herbella F, Schlottmann F, Patti M. Avaliação diagnóstica da acalasia do esôfago: dos sintomas à classificação de chicago. ABCD Arq Bras Cir Dig. 2018;31(2):e1376.

6. Aquino JLB, Leandro-Merhi VA, Mendonça JA, Mendes EDT, Clairet CMAV, Reis LO. Comparative analysis of late results of cervical esophagogastric anastomosis by manual and mechanical suture in patients submitted to esophageal mucosectomy through advanced megaesophagus. Arq Bras Cir Dig. 2019;32(4):e1462.

7. Ponciano $H$, Cecconello I, Alves L, Ferreira BD, Gama-Rodrigues J. Cardioplasty and Roux-en-Y partial gastrectomy (Serra-Dória procedure) for reoperation of achalasia. Arq Gastroenterol. 
2004;41(3):155-61.

8. Patti MG, Allaix ME. Recurrent symptoms after Heller myotomy for achalasia: evaluation and treatment. World J Surg. 2015;39(7):1625-30.

9. Herbella FA, Moura EG, Patti MG. Achalasia 2016: Treatment Alternatives. J Laparoendoscopic Adv Surg Tech A. 2017;27(1):6-11.

10. Sawas T, Ravi K, Geno DM, Enders F, Pierce K, Wigle D, Katzka DA. The course of achalasia one to four decades after initial treatment. Aliment Pharmacol Ther. 2017;45(4):553-560.

11. Oliveira GC, Lopes LR, Andreollo NA, Braga Nda S, Coelho Neto JS. Tratamento cirúrgico do megaesôfago no Hospital de Clínicas da UNICAMP
- fatores associados a melhores ou piores resultados. Rev Col Bras Cir. 2009;36(4):300-6.

12. Trevenzol HP. Operação de Serra-Dória no tratamento do megaesôfago operado com recidiva dos sintomas. [Dissertação]. São Paulo (SP): Universidade de São Paulo; 2003.

13. Veenstra BR, Goldberg FR, Bowers SP, Thomas $M$, Hinder RA, Smith CD. Revisional surgery after failed esophagogastric myotomy for achalasia: successful esophageal preservation. Surg Endosc. 2016;30(5):1754-61.

14. Andreollo NA, Lopes LR, Malafaia O. Cardiomiotomia à Heller: 100 anos de sucesso. ABCD Arq. Bras. Cir. Dig. 2014;27(1):1-1.
Received in: 28/12/2019

Accepted for publication: 29/03/2020

Conflict of interest: no.

Funding source: none.

\section{Mailing address:}

Luigi Carlo da Silva Costa

E-mail: luigicarlo.Ic@gmail.com

(c) (i) 